\title{
SYNTHESIS, SPECTRAL AND MOLECULAR MODELING STUDIES OF COUMARIN DERIVATIVES
}

\author{
P. VIJAY BHASKAR, A. RAMACHANDRAIAH*
}

Department of Chemistry, National Institute of Technology Warangal, Warangal, Telangana, India, 506004

Email: podarillu1@yahoo.co.in

Received: 03 Jan 2017, Revised and Accepted: 31 Apr 2017

\section{ABSTRACT}

Objective: To synthesize the 3-\{2-[N'-(1-Pyridin-2-yl-ethylidene)-hydrazino]-thiazol-4-yl $\}$ coumarins and study their spectral and molecular properties by using the spectroscopy and molecular modeling techniques.

Methods: Spectroscopy and Molecular modeling techniques

Results: The spectral behavior of 3-\{2-[N'-(1-Pyridin-2-yl-ethylidene)-hydrazino]-thiazol-4-yl $\}$ coumarins (1.1-1.3) in aqueous buffers of varied pH is presented. Spectrophotometry was utilized to study its proton and electron transfer characteristics with the support of molecular modeling studies. An excellent analytical method of assaying of (1.1-1.3) has been developed in Spectrophotometry at $\mathrm{pH}=6$. Molecular modeling on various acid-base conjugates of (1.1-1.3) and their several conformers has been carried out to arrive at the thermodynamic and conformational issues to correlate the spectral and electrochemical observations.

Conclusion: Electron transfer (ET) has been increasingly implicated as a biochemical pathway for the pharmacologic action of a variety of biological active compounds. These studies helps to understand the active form of the biological active compounds may have a catalytic function as an intermediary in passing electrons from a donor, such as DNA, protein, or an ET chain, to an acceptor, thereby exercising an influence on normal or aberrant ET chains, ion movements, membrane potentials, and oxidative stress. The actual agent may be the biological active compounds itself or a derived metabolite, such as a metal complex, oxidative product, or protonated form.

Keywords: Coumarin, Acid-base equilibria, Molecular modeling, Isosbestic points, Conformers

(C) 2017 The Authors. Published by Innovare Academic Sciences Pvt Ltd. This is an open access article under the CC BY license (http://creativecommons.org/licenses/by/4.0/) DOI: http://dx.doi.org/10.22159/ijcpr.2017v9i3.19984

\section{INTRODUCTION}

Coumarin derivatives are of interest because of their physiological, photodynamic, anticoagulant, spasmolytic, bacteriostatic and antitumor activity. They are also extensively used as analytical reagents. Coumarins and their derivatives have been studied extensively for their complexation with metal ions. A number of dioxouranium(VI) and titanium(IV) complexes with hydroxycoumarins, e. g., 3-hydroxycoumarin and 7,8--dihydroxy-4methylcoumarin, etc., have been studied spectrophotometrically and it has been observed that depending upon $\mathrm{pH}, 1: 1,1: 2$ and 1:3 complexes are formed in the solution. Hydrazinyl thiazol coumarins are extended derivatives of the chromone-2-one nucleus and find numerous therapeutic applications [1-6]. These schiff bases have evinced considerable research interest among chemists for their versatile spectral behaviour with a mechanism that varies with the solvent, $\mathrm{pH},[7-10]$.

Keeping the few and importance of the Coumarin few 2-Acetyl pyridine derivative of Coumarin were synthesized. The detail synthesis and purification of 3-\{2-[N'-(1-Pyridin-2-yl-ethylidene)hydrazino]-thiazol-4-yl\}coumarin and extraction of pure samples of the remaining four drugs are summarized here below.

3-\{2-[N'-(1-Pyridin-2-yl-ethylidene)-hydrazino]-thiazol-4-yl\} coumarin compound and its bromine derivatives were synthesized according to the reported procedure [5]. The chemical structure of this series is shown below. In this paper, we present the detailed spectral, and molecular modelling investigations of some selected schiff bases shown in 1.1, 1.2 and 1.3.

The procedure of the synthesis of $3-\left\{2-\left[N^{\prime}-(1-P y r i d i n-2-y]-\right.\right.$ ethylidene)-hydrazino]-thiazol-4-yl $\}$ coumarins, is presented here briefly as a typical case.

A mixture of 3-(2-bromoacetyl)coumarin (0.01 moles) and thiosemicarbazide ( 0.01 moles) was placed in a flask to which was added $10 \mathrm{ml}$ of 2-acetyl pyridine and stirred for $30 \mathrm{~min}$ at room temperature. The solventless reaction mixture was eventually washed with methanol and the washings were collected and kept for standing overnight. The crystalline solid separated was filtered and recrystallized from methanol again. The details of acid-base spectral, electrochemical and molecular modeling studies of 1.1-1.3 are presented in this paper.

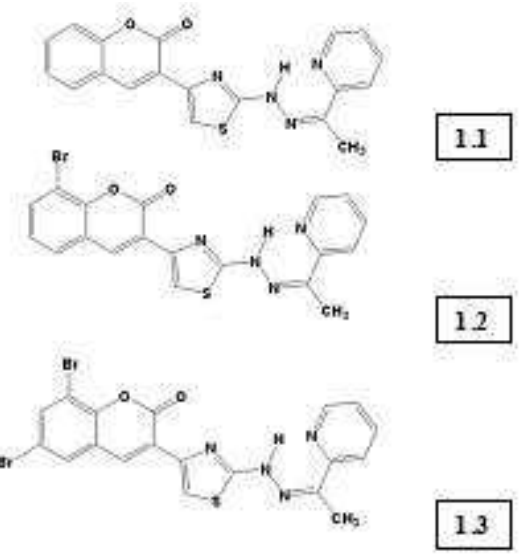

These compounds have been characterized by IR, UV-Visible, NMR and spectral analysis. The physical and analytical data of these compounds are collected in table 1.

The IR, UV-Visible, NMR and Mass spectra for 1.1 are shown in fig. 14 and corresponding data is presented in table 2 respectively.

\section{MATERIALS AND METHODS}

The electronic spectra and other photometric measurements of the compounds and reaction mixtures were recorded on an Analytic 
Jena Specord Model 250 (spectrophotometer). The $1 \mathrm{~cm}$ path length cuvetts were kept in double-walled constant temperature cuvett holder to keep the sample solutions at a constant temperature. An INSREF model cryostatic constant temperature circulating liquid bath was used for thermostatting the cuvette frame and the containers of solutions.

IR spectra was taken on Perkin Elmer FT-IR model. 1H NMR spectra of 3$\{2$-[N'-(1-Pyridin-2-yl-ethylidene)-hydrazino]-thiazol-4-yl $\}$ coumarin was taken on Bruker Avance $300 \mathrm{mHz}$ Fourier Transform Nuclear Magnetic Resonance Spectrometer with Tetramethylsilane (TMS) as an internal reference. Mass Spectra was taken on Waters Quattro Micro LC-MS/MS Spectrometer at $3.25 \mathrm{eV}$.

The $\mathrm{pH}$ of the buffers, stock solutions and reaction mixtures were measured by an Orion Model EA 940 Expandable Ion Meter equipped with 91-01 Ag|AgCl, combined glass electrode. Molecular Modelling studies were performed by using the Chemoffice Pro Ultra 8.0 version.

\section{RESULTS AND DISCUSSION}

\section{Spectral studies of 1.1-1.3}

\section{Infrared spectra}

The Fourier transform infrared spectra (FTIR) have been recorded for 1.1-1.3 and a typical one is posted in fig. 1. The compounds 1.11.3 are expected to show stretching frequencies related to- $\mathrm{C}=\mathrm{N}$-and$\mathrm{C}=0$ (lactone) besides several others. The peak at $\sim 1700 \mathrm{~cm}-1$ is due to lactone group and that at $\sim 1605 \mathrm{~cm}-1$ is due to- $\mathrm{C}=\mathrm{N}$-group.

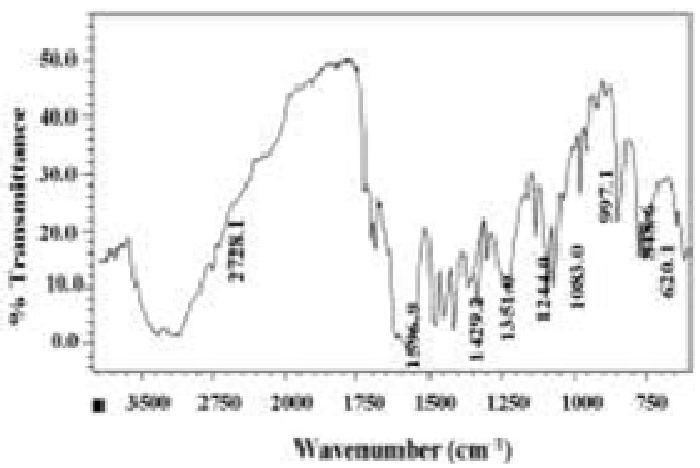

Fig. 1: FTIR spectrum of 1.1 in its $\mathrm{KBr}$ pellet

\section{Proton NMR spectra}

Fig. 2 shows the NMR spectral pattern of 1.1. The multiplet at $\delta$ 7.38.3 is due to aromatic protons and one azomethine proton. The doublet at $\delta 8.5$ is due to the protan on $\mathrm{C} 5$ of thiazole. The $\mathrm{NH}$ proton (D2O exchangeable) appeared as a singlet at $\delta 11.50$. The-CH3 proton appeares as a singlet at $\delta$ 2.4. The other two compounds also have shown similar NMR spectra compatible to their structures. Important NMR data are presented in table 2.

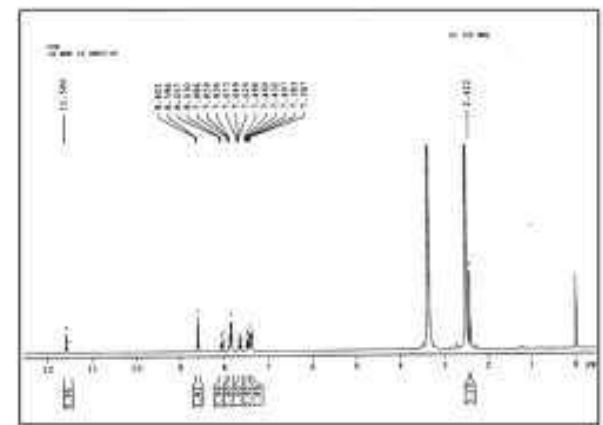

Fig. 2: Proton NMR spectral pattern of 3.1 (DMSO-d6) mass spectral studies

The mass spectrum of 1.1 is shown in fig. 3. Molecular ion of 1.1 is at $\mathrm{m} / \mathrm{z} 363$. Relevant mass spectral data are placed in table 3 .

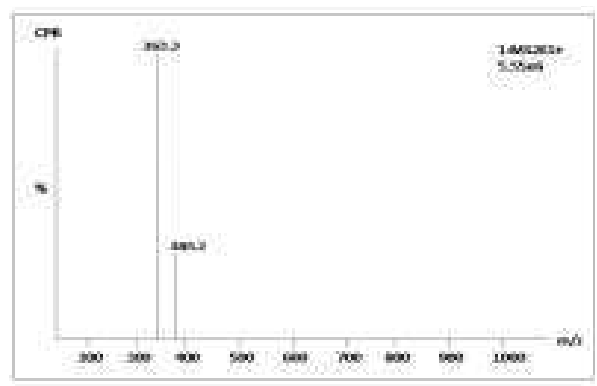

Fig. 3: Mass spectrum of 1.1

Table 1: Analytical data of 1.1, 1.2 and 1.3

\begin{tabular}{|c|c|c|c|c|c|c|c|c|}
\hline \multirow[t]{2}{*}{ Compound } & \multirow[t]{2}{*}{ Molecular formula } & \multirow[t]{2}{*}{ Colour } & \multirow{2}{*}{$\begin{array}{l}\text { Mol. } \\
\text { Wt }\end{array}$} & \multirow{2}{*}{$\begin{array}{l}\text { Kax } \\
109 \\
\end{array}$} & \multirow[t]{2}{*}{ M. P (oC) } & \multicolumn{3}{|c|}{ Elemental Analysis@ } \\
\hline & & & & & & $\mathrm{C} \%$ & H\% & N\% \\
\hline 1.1 & C19H14N402S & $\begin{array}{l}\text { Light } \\
\text { Yellow }\end{array}$ & 362.0 & 3.981 & 305 & $\begin{array}{l}65.70 \\
(62.97)\end{array}$ & $\begin{array}{l}4.11 \\
(3.89)\end{array}$ & $\begin{array}{l}17.51 \\
(15.46)\end{array}$ \\
\hline 1.2 & $\mathrm{C} 19 \mathrm{H} 13 \mathrm{~N} 402 \mathrm{SBr}$ & $\begin{array}{l}\text { Dark } \\
\text { Yellow }\end{array}$ & 439.9 & 5.011 & 295 & $\begin{array}{l}51.60 \\
(51.77)\end{array}$ & $\begin{array}{l}2.73 \\
(2.97)\end{array}$ & $\begin{array}{l}9.50 \\
(12.70)\end{array}$ \\
\hline 1.3 & C19H12N402SBr2 & $\begin{array}{l}\text { Light } \\
\text { Brown }\end{array}$ & 517.9 & 6.310 & 308 & $\begin{array}{l}43.79 \\
(43.87)\end{array}$ & $\begin{array}{l}2.13 \\
(2.33)\end{array}$ & $\begin{array}{l}8.06 \\
(10.77)\end{array}$ \\
\hline
\end{tabular}

@Values in the parentheses are calculated for the formulae

\section{Electronic spectra and acid-base equilibria}

The electronic spectrum of a methanolic solution of 1.1 is shown in fig. 4. Two distinct electronic transitions observed at $\sim 299$ and $\sim 347 \mathrm{~nm}$. These bands are tentatively assigned to $\pi \rightarrow \pi^{*}$ and $n \rightarrow \pi^{*}$ transitions respectively of the azomethine group, predominately.

The electronic spectra of 1.1 in various aqueous buffers are shown in fig. 5. The spectra exhibit a small amount of bathochromic shift with increased $\mathrm{pH}$. The spectra of the other compounds are similar to this one.
There are three potentially basic nitrogen atoms in 1.1-1.3, viz, the pyridinic, thiazolic and the hydrazenic schiff base nitrogens. The hydrazenic hydrogen has been reported to be usually acidic and that it undergoes Wolf-Kischner kind of transformation [11]. It may be tentatively suggested that the compounds exhibit acid-base equilibria as in Scheme 1. Even though it is likely that 1.1 is triply protonated to render $1 \mathrm{H} 33+$, the pKa of the latter $(1 \mathrm{H} 33+)$ might be very low due to columbic repulsions. Instead, the species, $1 \mathrm{H} 22+$, must be very stabilized by intramolecular hydrogen bonds and tautomerism, as indicated in Scheme 1. 


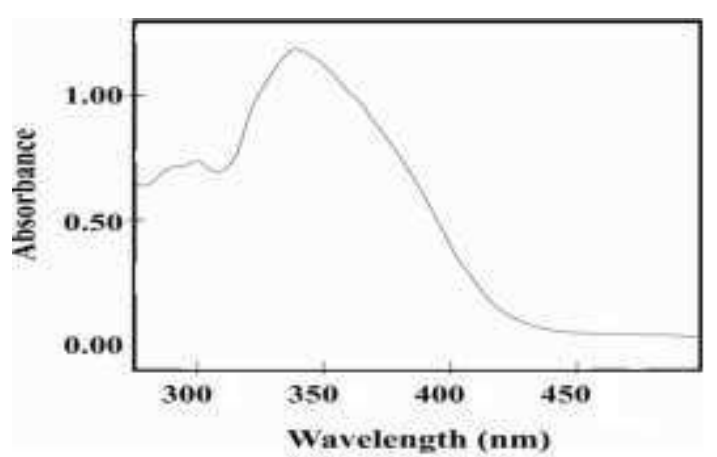

Fig. 4: Electronic spectrum of 1.1 in methanol (1.85 x 10-5 M)

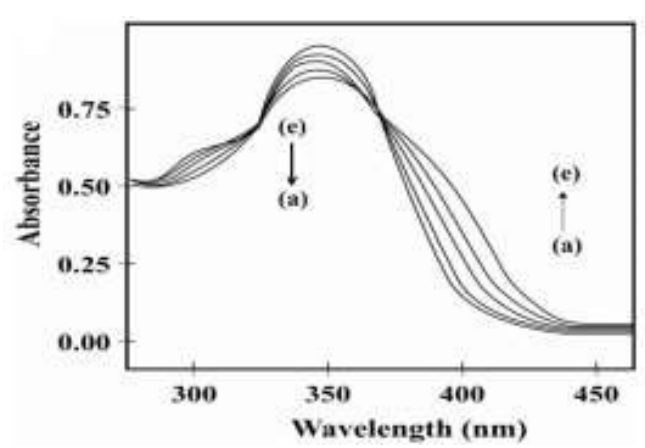

Fig. 5: UV-Vis spectra of $1.1(1.65 \times 10-5 \mathrm{M})$ at $\mathrm{pH}$ (a) 2.17, (b) 5.35, (c) 7.85, (d) 9.64 and (e) 10.28

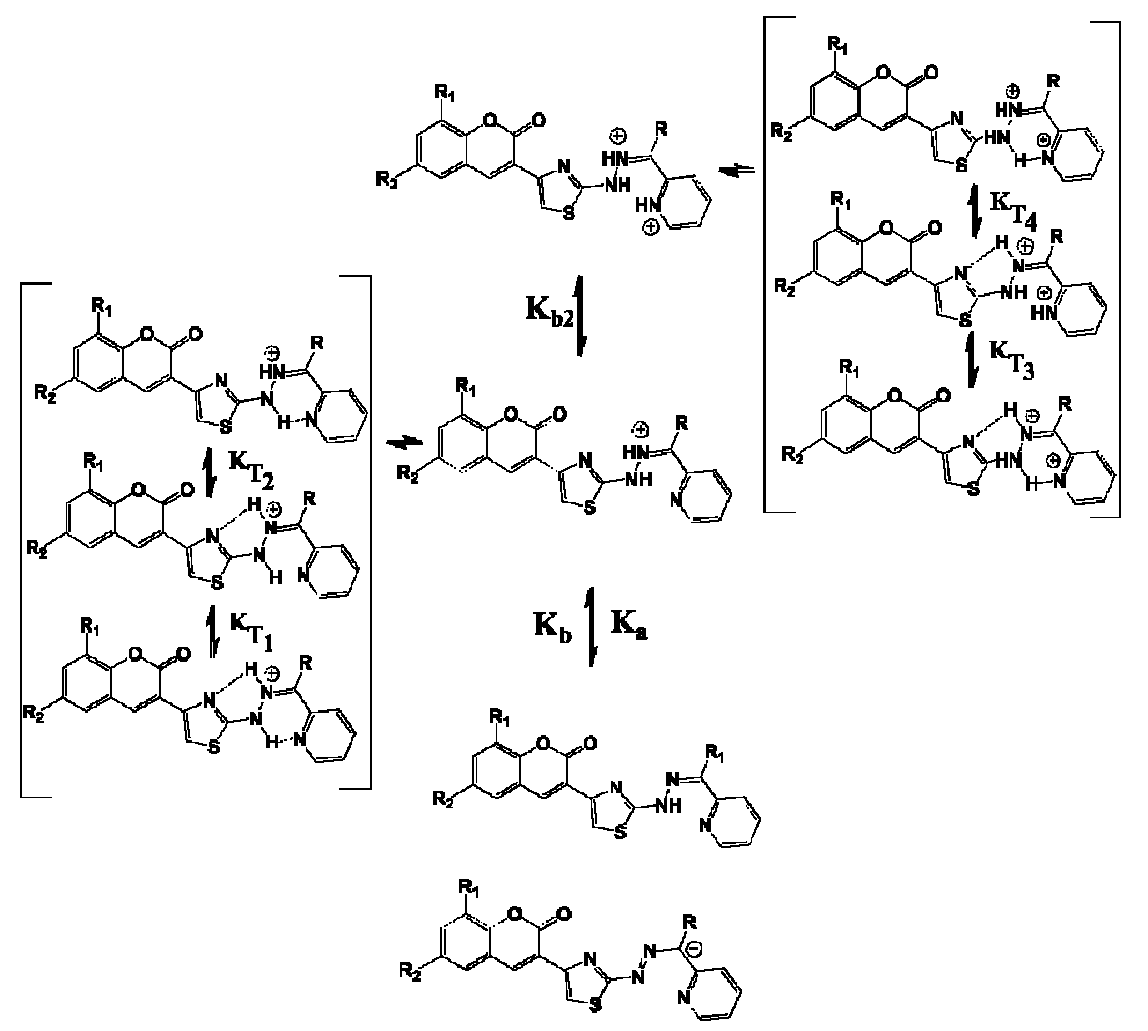

Scheme 1

Whether the nitrogens are protonated or not, the $\pi \rightarrow \pi^{*}$ and $n \rightarrow \pi^{*}$ transitions may hardly be influenced because the electron pairs of all sp2 nitrogens are orthogonal to the ring systems. Thus, one expects a poor effect of $\mathrm{pH}$ on the low energy uv-visible spectral profile of 1.1. Fig. 5 is indicative of this fact.

Molecular modelling done on all these species also gave varied values for the HOMO and LUMO energies but the energy gap between the HOMO and LUMO of 1.1 and hence, $\lambda$ max were found to be marginally variable with acid-base conjugate species. By plotting absorbance at $\sim 350 \mathrm{~nm}$ with $\mathrm{pH}$, we evaluated the $\mathrm{pKa}$ (for $1 \mathrm{H}+$ ) and $\mathrm{pKb}$ (for 1.1). The spectral and thermodynamic data of 1.1-1.3 are presented in table 3.

\section{Coordination chemistry of 1.1-1.3}

Compounds, 1.1-1.3, have several coordinating centers or atoms such as azomethine, heterocyclic nitrogens and phenolic or carbonyl oxygen that can bind to metal ions. These compounds are expected to be potential bidentate ligands.

Most of the heterocyclic drugs owe their pharmacokinetic mechanism to electron transfer process often catalyzed by metalloenzymes. Metal coordination alters the electrochemical behaviour of ligand. Similarly the electrochemistry of the metal ion, in turn, would be modified upon coordination.

We have made an investigation into the metal-ligand interactions of 1.1-1.3. UV-Visible spectrophotometry has been utilized to elucidate and confirm the possible complexation that occurs between the compounds 1.1-1.3, and Cu2+ion. The spectral pattern of the complex must be different from those of the corresponding pure ligand and metal. The spectra of the ligand in the absence and in presence of metal are shown in fig. 6.

The spectral profiles reveal that there could be a complexation between $\mathrm{Cu} 2+, \mathrm{Ni} 2+, \mathrm{Co} 3+\mathrm{i}$ n and the coumarin ligands. The fig. 7 shows the formation of the complexation between Co3+ion and the coumarin ligands. The electrochemical behaviour in the absence and in the presence of metal would indicate the way in which the metal ion coordinates to the ligand molecule. AJob's plot also gave the M: L ratio as 1:2. The Job's plot is shown in fig. 8 and plausible structure for the complex shown in fig. 9. 
Table 2: Spectral data of 1.1, 1.2 and 1.3

\begin{tabular}{|c|c|c|c|c|c|c|}
\hline \multirow[t]{2}{*}{ Compound } & \multirow{2}{*}{$\begin{array}{l}\text { Molecular } \\
\text { formula }\end{array}$} & \multirow{2}{*}{$\begin{array}{l}\text { UV-visible } \\
\text { Spectr al data } \\
\lambda(\mathrm{nm})\end{array}$} & \multicolumn{4}{|c|}{ Infrared spectral data( } \\
\hline & & & $\begin{array}{l}\text { Exocyclic } \\
-\mathrm{C}=\mathrm{N}-\end{array}$ & $\begin{array}{l}\text { Lactone } \\
-\mathrm{C}=0 \text { - }\end{array}$ & NMR spectral data $(\delta$ ppm) & $\begin{array}{l}\text { Mass spectral data } \\
(\mathrm{m} / \mathrm{z})\end{array}$ \\
\hline 1.1 & C19H14N402 S & 347 & 1596 & 1720 & $\begin{array}{l}\delta 11.6(\mathrm{~s}), \delta 8.6(\mathrm{~m}), \delta 8.1(\mathrm{~d}), \delta 7.8(\mathrm{~m}) \\
\delta 7.6(\mathrm{t}), \delta 7.3(\mathrm{~m}), \delta 2.4(\mathrm{~s})\end{array}$ & 363.2 \\
\hline 1.2 & C19H13N4O2 SBr & 342 & 1664 & 1716 & $(\mathrm{~s}), \delta 7.5(\mathrm{~m}), \delta 7.7(\mathrm{~m}), \delta 7.3(\mathrm{~m}), \delta 2.5(\mathrm{~s})$ & 441.3 \\
\hline 1.3 & $\begin{array}{l}\text { C19H12N4O2 } \\
\text { SBr2 }\end{array}$ & 340 & 1557 & 1732 & $\begin{array}{l}(\mathrm{d}), \delta 8.4(\mathrm{~s}), \delta 8.1(\mathrm{~d}), \delta 8.0(\mathrm{~s}), \delta 7.8 \\
(\mathrm{~d}), \delta 7.7(\mathrm{~m}), \delta 7.6(\mathrm{~d}), \delta 2.8(\mathrm{~s})\end{array}$ & 520.3 \\
\hline
\end{tabular}

Table 3: Spectral and thermodynamic data of 1.1\#

\begin{tabular}{|c|c|c|c|c|c|c|c|}
\hline Compound & Low 0 & High 0 & Iso 0 & pKa & pKb & Ka $\times 105$ & Go \\
\hline 1.1 & $\begin{array}{l}351.6 \\
(5405)\end{array}$ & $\begin{array}{l}399.1 \\
(2276)\end{array}$ & $\begin{array}{l}367.3 \\
(3756)\end{array}$ & 4.4 & 9.6 & 3.981 & 25.12 \\
\hline 1.2 & $\begin{array}{l}349.0 \\
(5303)\end{array}$ & $\begin{array}{l}401.4 \\
(2232)\end{array}$ & $\begin{array}{l}365.3 \\
(3639)\end{array}$ & 4.3 & 9.7 & 5.011 & 24.55 \\
\hline 1.3 & $\begin{array}{l}354.5 \\
(5292)\end{array}$ & $\begin{array}{l}402.2 \\
(2198)\end{array}$ & $\begin{array}{l}369.6 \\
(3617)\end{array}$ & 4.2 & 9.8 & 6.310 & 23.98 \\
\hline
\end{tabular}

\# in nm; (in lit mol-1 cm-1); Ka and Go (in kJ mol-1) are for the process, $1 \mathrm{H}+1$; low and high are wavelengths below and above the isosbestic wavelength, iso, respectively

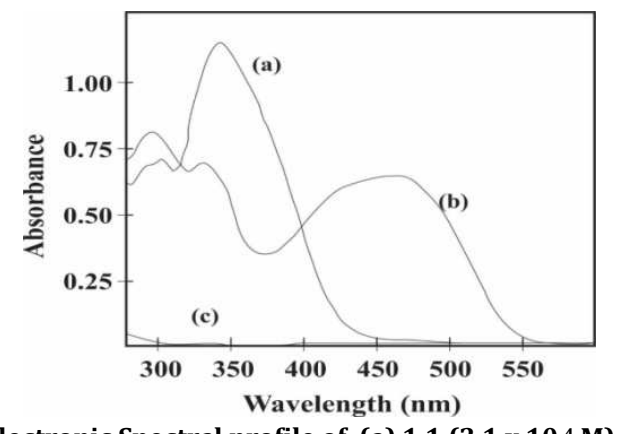

Fig. 6: Electronic Spectral profile of (a) $1.1\left(3.1 \times 10^{-4} \mathrm{M}\right)$ and (b) $\left.\mathrm{L}_{2}-\mathrm{Cu}\right]^{2+}\left(3.1 \times 10^{-4} \mathrm{M}\right)$ Complex and $(\mathrm{c}) \mathrm{Cu}^{+2}$ solution $\left(1.65 \times 10^{-4} \mathrm{M}\right)$ where $L=1.1-1.3$

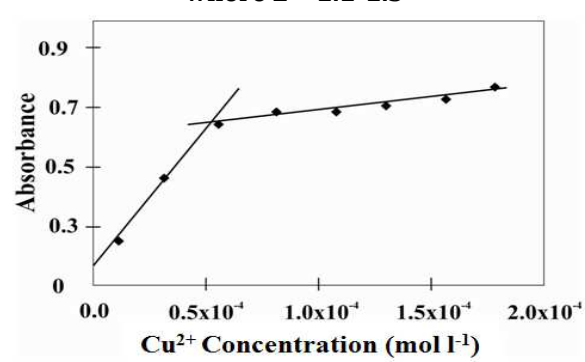

Fig. 8: Job's plot for complexation of 1.1 with $\mathrm{Cu}^{2+}$ (Ligand concentration $1.1 \times 10^{-4} \mathrm{M}$ )

\section{Assaying of 1.1-1.3}

The acid-base equlibria features of 1.1-1.3 suggest reliable spectrophotometric analysis of 1.1. Our studies suggest up 10 nanomolar sensitivity acidic buffers. In fig. 10 is shown a typical medium range calibration plot obtained for 1.1.

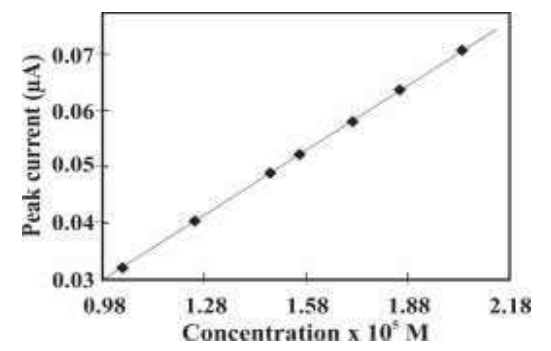

Fig. 10: The calibration plot of 3.1 in buffer of $\mathrm{pH}=6$

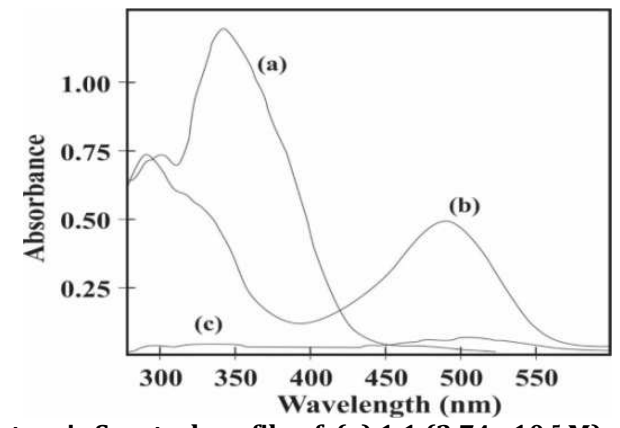

Fig. 7: Electronic Spectral profile of (a) $1.1\left(3.74 \times 10^{-5} \mathrm{M}\right)$ and (b) [ $\mathrm{L}_{2^{-}}$ $\mathrm{Co}^{3+}\left(3.74 \times 10^{-5} \mathrm{M}\right)$ complex and (c) $\mathrm{Co}^{3+}$ solution $\left(1.87 \times 10^{-5} \mathrm{M}\right)$ where $L=1.1-1.3$

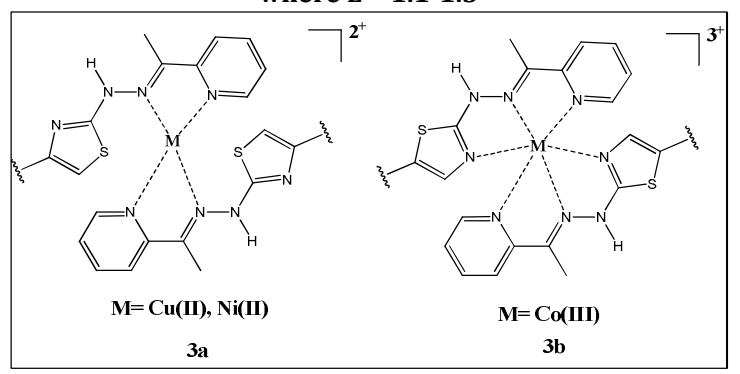

Fig. 9: Possible coumarin Schiff base complexes with $\mathrm{Cu}^{2+}, \mathrm{Ni}^{2+}$ and $\mathrm{Co}^{3+}$

\section{Molecular modeling}

Molecular modeling studies have been done on the present series of compounds, 1.1-1.3, to understand the stability, intramolecular hydrogen bonding and conformational analysis to verify the mechanisms proposed for the thermodynamic, spectroscopic and electrochemical behavior of the compounds. The energy minimized structures of 1.1 in their stereographical projections generated by MM2 of Chem Office Ultra software are shown in fig. 11 and the numbering pattern is followed as shown in stable conformer. Thermodynamic parameters are calculated for the protonated and deprotonated and unprotonated forms of compounds 1.1-1.3. These values are presented in table 4.

The conformational analysis was done on all LH32+, LH, L-forms of 1.1 was done. For this purpose, a systematic energy search of the molecule was done at several conformational positions around each rotatable but noteworthy single bond.

From many conformers thus generated, the least energy conformer chosen by energy minimization using MM2. It was observed that 
coumarin ring deviates from coplanarity with the central thiazole ring while hydrazine pyridine ring is nearly perpendicular to the thiazole ring (fig. 11). The steric energies and heats of formations were calculated for every 20 degrees of rotation around selected-C$\mathrm{N}$-bond and-N-N-bond. The plot of torsional angle vs torsional energy plots of 1.1 are shown in fig. 12 .

The quantum mechanical HOMO-LUMO orbital energy calculations have been used for computing the expected gas-phase electronic transitions. These values are also collected in table 6 along with the experimental spectral data. But for the parent species, 3.1, the theoretical and experimental absorption maxima are in great agreement. The HOMO-LUMO molecular orbital surfaces and their energies are shown in fig. 13.
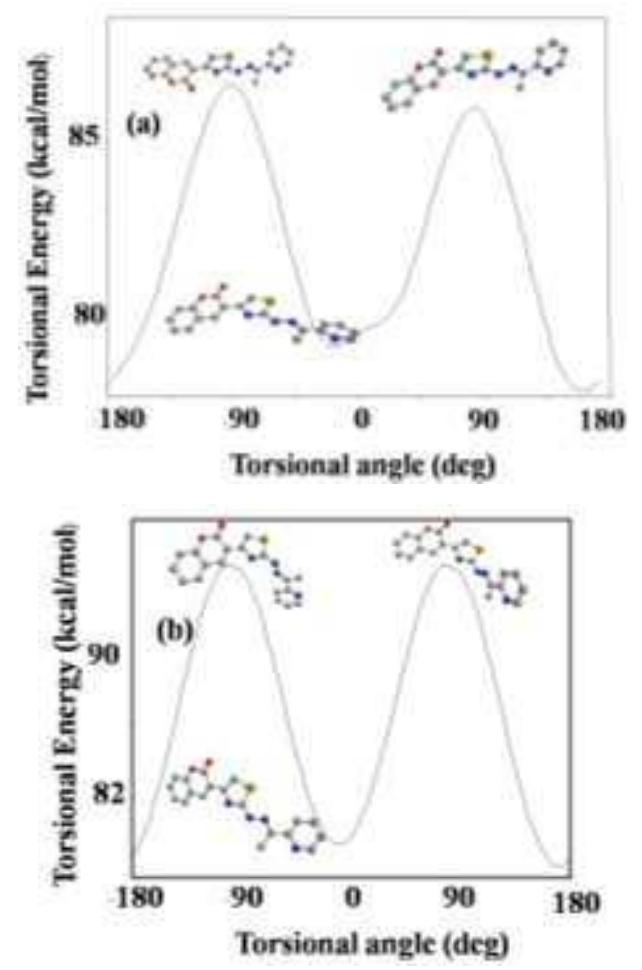

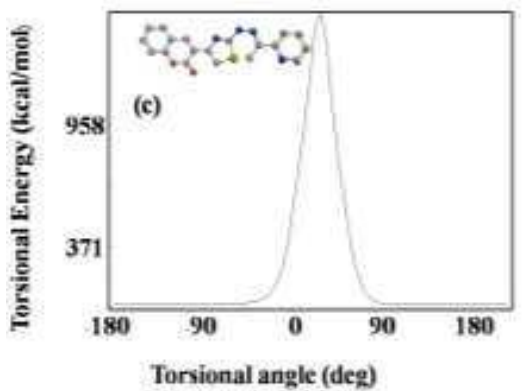

Fig. 12: Conformational analysis of 1.1 around a)-C12-C8-, b)N17-C15-and c)-N17-N18

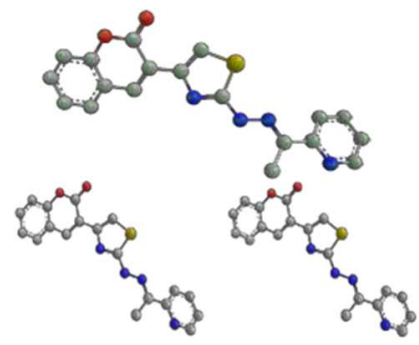

Fig. 11: Energy minimized 1.1 generated from energy minimization through MM2 calculations (hydrogen

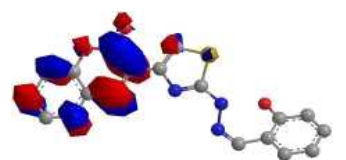

LUMO

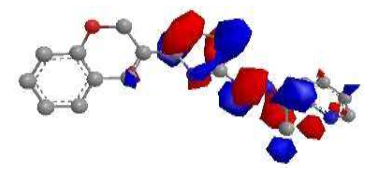

HOMO

Fig. 13: HOMO, LUMO molecular orbitals of 1.1

Table 4: Molecular modeled thermodynamic, dipole moment, dihedral angle 0 and spectral data of 1.1, 1.2 and 1.3

\begin{tabular}{|c|c|c|c|c|c|c|c|c|c|c|}
\hline \multirow[t]{2}{*}{ Property } & \multirow[t]{2}{*}{ System\# } & \multicolumn{4}{|l|}{ LH22+ } & \multicolumn{5}{|l|}{ LH+ } \\
\hline & & LH33+ & $\overline{\mathbf{A P}}$ & AT & PT & A & $\mathbf{P}$ & $\mathbf{T}$ & $\mathbf{L}$ & L- \\
\hline Hof & 1.1 & 150.9 & 62.7 & 49.0 & 33.4 & 6.6 & 7.2 & 3.1 & 16.6 & 19.1 \\
\hline \multirow[t]{2}{*}{ (kJ mol-1) } & 1.2 & 159.5 & 65.6 & 55.6 & 37.4 & 11.0 & 10.1 & 6.6 & 18.3 & 19.7 \\
\hline & 1.3 & 162.5 & 67.8 & 58.3 & 40.0 & 13.0 & 11.8 & 8.9 & 19.7 & 21.1 \\
\hline Dipole & 1.1 & 4.1 & 6.0 & 3.4 & 3.4 & 3.4 & 5.4 & 2.6 & 2.8 & 6.8 \\
\hline Moment & 1.2 & 6.0 & 7.9 & 5.5 & 5.2 & 5.4 & 7.1 & 5.1 & 5.0 & 7.7 \\
\hline \multirow[t]{3}{*}{ (DB) } & 1.3 & 7.0 & 9.0 & 6.6 & 6.3 & 6.5 & 8.2 & 6.2 & 6.0 & 8.8 \\
\hline & & 2.6 & 11.1 & 12.0 & 5.1 & 25.1 & 10.9 & 7.7 & 21.5 & 6.8 \\
\hline & 1.1 & 13.3 & 45.0 & 18.2 & 14.1 & 26.7 & 2.4 & 10.7 & 12.3 & 11.4 \\
\hline Dihedral & & 8.9 & 0.3 & 4.1 & 6.0 & 25.6 & 8.3 & 31.3 & 36.1 & 89.0 \\
\hline Angles & 1.2 & 29.7 & 7.9 & 8.4 & 6.4 & 25.7 & 10.1 & 11.3 & 1.9 & 7.1 \\
\hline 7-8-12-13; & & 14.8 & 46.0 & 18.0 & 4.5 & 27.1 & 1.9 & 9.2 & 1.7 & 9.9 \\
\hline $14-15-17-$ & & 7.9 & 37.7 & 8.4 & 10.1 & 27.3 & 7.7 & 33.1 & 22.9 & 95.6 \\
\hline 18 & 1.3 & 30.1 & 8.8 & 8.3 & 6.5 & 27.2 & 11.2 & 8.7 & 0.5 & 5.8 \\
\hline $18-19-21-22$ & & 15.8 & 46.3 & 19.0 & 3.0 & 28.1 & 2.0 & 9.7 & 1.7 & 9.7 \\
\hline \multirow[t]{3}{*}{ (deg) } & & 6.9 & 38.0 & 9.8 & 9.6 & 29.3 & 7.4 & 32.6 & 23.0 & 97.2 \\
\hline & & 2.5 & 1.7 & 1.1 & 2.4 & 1.8 & 2.2 & 2.9 & 3.2 & 0.9 \\
\hline & 1.1 & 482 & 692 & 1070 & 502 & 676 & 541 & 411 & 370 & 1332 \\
\hline$\$(\mathrm{eV})$ & 1.2 & 2.6 & 1.5 & 1.0 & 2.1 & 1.6 & 2.2 & 2.6 & 3.3 & 0.8 \\
\hline \multirow[t]{3}{*}{$\max (\mathrm{nm})$} & & 456 & 771 & 1175 & 582 & 747 & 551 & 456 & 365 & 1577 \\
\hline & 1.3 & 2.6 & 1.6 & 1.0 & 2.0 & 1.7 & 2.6 & 2.6 & 3.1 & 0.8 \\
\hline & & 451 & 765 & 1158 & 585 & 707 & 449 & 455 & 380 & 1546 \\
\hline
\end{tabular}

\# A, P and T mean hydrazone, pyridine and thiazole nitrogen sites respectively; \$ energy gap between LUMO and HOMO orbitals of the modeled global minimum energy structure 


\section{CONCLUSION}

In this study 3-\{2-[N'-(1-Pyridin-2-yl-ethylidene)-hydrazino]thiazol-4-yl,\} coumarins were synthesized and the structures were characterised by UV, IR, NMR and Mass techniques. The electronic transfer characteristics were studied by using the Spectroscopy and Molecular modeling studies.

\section{ACKNOWLEDGEMENT}

The authors would like to thank Department of chemistry, NITW, Warangal for providing the facility to carry out of this research work.

\section{CONFLICT OF INTERESTS}

\section{Declare none}

\section{REFERENCES}

1. Wawzonek 0. Heterocyclic Compounds. John Wiley and Sons. New York; 1975. p. 173.

2. Dean FM, Butter Worths. Naturally occurring oxygen ring compounds. $2^{\text {nd }}$ ed. London; 1963. p. 75.

3. Livingtone R. Rod's chemistry of carbon compounds. 4th ed. Elsevier Amsterdam: 1977. p. 66.
4. Stauton J. Comprehensive organic chemistry. 4th ed. Oxford; 1979. p. 629.

5. Kartritzky AR, Rees CW. Comprehensive heterocyclic chemistry. Pergaman Press Oxford; 1984. p. 3.

6. Hantzsch H. Application of NAD(P)H model hantzsch 1,4dihydropyridine as a mild reducing agent in preparation of cyclo compounds. Weber J Ber 1887;20:311.

7. Hantzsch H. Index to jersey county births-S. Ann 1888;1:249.

8. Dadson RM, King LC. Physical and inorganic chemistry. J Am Chem Soc 1950;92:2242.

9. King LC, Hlavacek RJ. Theory, Production and Mechanism of Formation of Monodispersed Hydrosols. J Am Chem Soc 1950;92:722.

10. Ju Luirie. Handbook of Analytical Chemistry. Mir Publishers Moscow; 1978.

11. Hutchins $\mathrm{O}$, Hutchins MK. Wolff-Kishner reduction reactions using a solar irradiation heat source and a green solvent system. Compr Org Synth 1991;8:327-43.

\section{How to cite this article}

- $\quad$ P Vijay Bhaskar, A Ramachandraiah. Synthesis, spectral and molecular modeling studies of coumarin derivatives. Int J Curr Pharm Res 2017;9(3):127-132. 